\title{
Treatment Outcomes of Childhood Tuberculous Meningitis in a Real-World Retrospective Cohort, Bandung, Indonesia
}

\author{
Heda M. Nataprawira, ${ }^{1}$ Fajri Gafar, ${ }^{1}$ Nelly A. Risan, Diah A. Wulandari, Sri Sudarwati, \\ Ben J. Marais, Jasper Stevens, Jan-Willem C. Alffenaar, Rovina Ruslami
}

\begin{abstract}
We retrospectively evaluated clinical features and outcomes in children treated for tuberculous meningitis (TBM) at Hasan Sadikin Hospital, Bandung, Indonesia, during 2011-2020. Among 283 patients, $153(54.1 \%)$ were <5 years of age, and $226(79.9 \%)$ had stage II or III TBM. Predictors of in-hospital death $(n=44[15.5 \%])$ were stage III TBM, hydrocephalus, male sex, low-income parents, seizures at admission, and lack of bacillus Calmette-Guérin vaccination. Predictors of postdischarge death $(n=18$ [6.4\%]) were hydrocephalus, tuberculoma, and lack of bacillus Calmette-Guérin vaccination. At treatment completion, $91(32.1 \%)$ patients were documented to have survived, of whom $33(36.3 \%)$ had severe neurologic sequelae and $118(41.7 \%)$ had unknown outcomes. Predictors of severe neurologic sequelae were baseline temperature $\geq 38^{\circ} \mathrm{C}$, stage III TBM, and baseline motor deficit. Despite treatment, childhood TBM in Indonesia causes substantial neurologic sequelae and death, highlighting the importance of improved early diagnosis, better tuberculosis prevention, and optimized TBM management strategies.
\end{abstract}

Tuberculosis (TB) is a major global health problem, 1 and an estimated 1.2 million new pediatric cases and 230,000 deaths occurred in children $<15$ years of age in 2019 (1). Tuberculous meningitis (TBM) is the most severe manifestation of TB, leading to high rates of childhood TBM mortality, at an average of $19 \%$, and neurodisability in $>50 \%$ of survivors, even when

Author affiliations: Hasan Sadikin Hospital, Bandung, Indonesia (H.M. Nataprawira, N.A. Risan, D.A. Wulandari, S. Sudarwati); Universitas Padjadjaran, Bandung, Indonesia (H.M. Nataprawira, N.A. Risan, D.A. Wulandari, S. Sudarwati, R. Ruslami); University of Groningen, Groningen, the Netherlands (F. Gafar, J. Stevens); Children's Hospital at Westmead, Sydney, New South Wales,

Australia (B.J. Marais); University of Sydney, Sydney (B.J. Marais, J.-W.C. Alffenaar); Westmead Hospital, Sydney (J.-W.C. Alffenaar)

DOI: https://doi.org/10.3201/eid2803.212230 treatment is provided (2). After infection with $M y$ cobacterium tuberculosis, children $<2$ years of age are at the highest risk for progression to miliary TB and TBM, most likely because of their immature immune systems (3). Childhood and adolescent TB has historically been neglected $(4,5)$; however, recently this condition has begun to gain priority as a focus of global collaborative efforts toward ending TB in children and adolescents (6).

The most important predictors of favorable outcome in childhood TBM are early diagnosis and immediate initiation of treatment (2). However, incomplete understanding of the pathogenesis, nonspecific symptoms, suboptimal performance of diagnostic tests, and the paucibacillary nature of the disease often result in a lengthy process of obtaining a definite diagnosis (7-9). Moreover, antimicrobial therapy as currently recommended by the World Health Organization (WHO) for the management of childhood TBM remains suboptimal $(9,10)$ and most likely contributes to poor outcomes. Summary estimates of neurologic sequelae and death associated with childhood TBM have been described in a meta-analysis, but predictors of these poor outcomes other than diagnosis in the most advanced disease stage were reported to have high heterogeneities across studies (2). Data on clinical features and treatment outcomes of childhood TBM from large cohorts of children outside of South Africa are limited (11-13). In settings in Indonesia, a few small studies have reported clinical outcomes of childhood TBM (14-16), but none have explored factors associated with the outcomes. This characterization is clinically relevant, enabling early and targeted interventions to optimize care

${ }^{1}$ These first authors contributed equally to this article. 
in this vulnerable population. In this context, our study aimed to assess clinical features of childhood TBM and to evaluate factors associated with poor outcomes, including in-hospital death, postdischarge death, and neurologic sequelae.

\section{Methods}

\section{Patients and Setting}

This real-world retrospective cohort study consecutively included children $<15$ years of age treated for TBM at the Department of Child Health of Hasan Sadikin Hospital, a national tertiary teaching hospital in Bandung, Indonesia, during January 2011-December 2020. The study was approved by the Independent Ethics Committee of Hasan Sadikin Hospital (approval no. LB.02.01/X.6.5/91/2021). Because of the retrospective nature of the study design, the Ethics Committee waived the need for written informed consent.

\section{Diagnosis}

We established TBM diagnosis on the basis of clinical, laboratory, and radiologic findings (17), combining medical history, physical and clinical examinations, tuberculin skin test, chest radiography, cerebrospinal fluid (CSF) analysis, and neuroimaging by using computed tomography (CT) scan. We performed microbiologic examination of CSF and non-CSF samples, including smear microscopy for acid-fast bacilli (AFB), culture for M. tuberculosis, and Xpert MTB/RIF assay, depending on sample availability. We assessed diagnostic certainty of definite, probable, or possible TBM by using uniform case definition criteria for TBM research (18) (Appendix Table 1, https://wwwnc.cdc. gov/EID/article/28/3/21-2230-App1.pdf). We presumed that patients had drug-susceptible TBM unless drug resistance was proven in Xpert MTB/RIF or drug-susceptibility testing. We excluded TBM patients with drug-resistant TB from the study.

\section{Treatment}

We based treatment regimens on the 2010 WHO guidelines in accordance with the Indonesian Paediatric Society guidelines for TBM treatment in children, consisting of daily isoniazid at $10 \mathrm{mg} / \mathrm{kg}$ (range $7-15 \mathrm{mg} / \mathrm{kg}$ ), rifampin at $15 \mathrm{mg} / \mathrm{kg}$ (range $10-20 \mathrm{mg} /$ $\mathrm{kg}$ ), pyrazinamide at $35 \mathrm{mg} / \mathrm{kg}$ (range $30-40 \mathrm{mg} / \mathrm{kg}$ ), and ethambutol at $20 \mathrm{mg} / \mathrm{kg}$ (range 15-25 mg/ $\mathrm{kg}$ ) for a 2-month intensive phase, followed by a 10-month continuation phase with isoniazid and rifampin at the same doses $(17,19)$. We administered all anti-TB drugs orally as fixed-dose combination or single-drug formulation tablets, where available. Patients received facility-based directly observed therapy (DOT) during hospitalization. After discharge, patients received home-based DOT under the supervision of parents or other family members. Most patients received adjunctive oral prednisone (2-4 mg/ $\mathrm{kg} / \mathrm{d}$ ) for the first 4-8 weeks, tapered according to the national guidelines (17). We treated patients with increased intracranial pressure with hypertonic saline or mannitol 20\% (0.5-1 g/ kg) every 8 hours. We performed ventriculoperitoneal shunt or extraventricular drain placements in patients with obstructive hydrocephalus, at the discretion of the neurosurgical team.

\section{Data Collection}

We collected individual patient data from hospital registry in a predefined form and appropriately deidentified the data before analysis. These data were demographic information (age, sex, parents' education and income, area of living, and length of hospital admission); medical history (HIV infection, bacillus Calmette-Guérin [BCG] vaccination, and TB contact history); clinical characteristics (symptoms of TBM, vital signs, nutritional status, physical and neurologic examinations, tuberculin skin test, Glasgow coma scale [GCS], and TBM staging); laboratory findings (CSF analysis, AFB microscopy, mycobacterial culture, and Xpert MTB/RIF test); radiographic findings (chest radiograph and neuroimaging); and other supporting data (corticosteroid therapy and in-hospital complications).

\section{Definitions}

We developed operational definitions for all variables (Appendix Table 2). We defined definite TBM as microbiologic confirmation of CSF and probable TBM as a total diagnostic score of $\geq 12$ when neuroimaging was available or $\geq 10$ when neuroimaging was unavailable. We defined possible TBM as a total score of 6-11 when neuroimaging was available or 6-9 when neuroimaging was unavailable (18). We classified TBM staging according to the modified British Medical Research Council grading system (20), as follows: stage I, GCS 15 without focal neurologic deficit; stage II, GCS 11-14, or 15 with focal neurologic deficit; and stage III, GCS $\leq 10$. Patients with known BCG vaccination included those who had a documented vaccination history at hospital admission or had a BCG scar in the deltoid region of the upper arm. Motor deficits included hemiparesis, quadriparesis, and diplegia. Other neurologic deficits were signs of upper motor neuron lesion and cranial nerve palsies. We performed motor, 
hearing, visual, and neurodevelopmental function assessments at treatment completion as indicated by the attending physicians (Appendix).

\section{Outcomes}

Outcomes of hospitalization were recovery (with or without disability), nonrecovery (persistent vegetative state and discharge against medical advice), and death. After 12 months of treatment, we reported the following outcomes: treatment completion, death, and lost to follow-up (LTFU; i.e., patients who stopped treatment for $\geq 2$ consecutive months). "Not evaluated" or "unknown treatment outcome" categories were patients who were transferred back to regional public hospitals or community health clinics for follow-up after discharge. We defined survival as being alive at treatment completion and neurologic sequelae as any motor, hearing, visual, or neurodevelopmental impairment that appeared during the illness and persisted through treatment completion.

\section{Data Analysis}

We evaluated associations of patient characteristics with poor outcomes. First, we compared patients who died during hospitalization (in-hospital death) with those who had recovered at the time of discharge; this definition excluded persistent vegetative state and discharge against medical advice. Second, we compared patients who died after discharge (postdischarge death) with those who completed treatment, regardless of their sequelae status; this definition excluded LTFU and unknown outcomes. Third, we compared survivors with neurologic sequelae with those without sequelae; this definition excluded death, LTFU, and unknown outcomes.

We used Cox proportional-hazards regression analysis to assess predictors of in-hospital death. We calculated time to death on the basis of length of stay by subtracting day of admission from day of death. Most patients were discharged within 2 months of hospitalization; in this case, we assumed that recovering patients (with or without disability) discharged before 2 months were alive until the end of 2 months, and thus we censored these patients in the Cox regression analysis. Because the time to death after discharge was not recorded, we assessed associated factors with postdischarge death and neurologic sequelae by using logistic regression analysis. We adjusted our multivariate models for age, sex, and TBM staging, and completed the models with variables showing a trend toward association in univariate analysis. We selected these variables by using backward deletion, and the final models retained all additional variables with a $\mathrm{p}$ value $<0.1$. For logistic regression analysis, we evaluated the goodness-of-fit of the final models by using Hosmer-Lemeshow test and performance by the area under the receiver operating characteristic curve. For Cox regression analysis, we checked proportional hazards assumption using Kaplan-Meier curve before fitting the model, and using log-minus-log survival curve after fitting the model. We used adjusted hazard ratios (aHRs) for Cox regression models and adjusted odds ratios (aORs) for logistic regression models, as well as 95\% CIs, to estimate the association between explanatory variables and outcomes. We defined statistical significance as $\mathrm{p}<0.05$. We performed all analyses by using IBM SPSS Statistics 26.0 (https:/ / www.ibm.com).

\section{Results}

\section{Clinical Characteristics}

During the study period (2011-2020), 286 children with TBM were treated at Hasan Sadikin Hospital; 3 patients with rifampin-resistant TB were excluded. No patients had concurrent bacterial meningitis. Among 283 included patients, 150 (53.0\%) were boys, $153(54.1 \%)$ were $<5$ years of age, $183(64.7 \%)$ were malnourished, $226(79.9 \%)$ had stage II or III TBM, and $51(18.0 \%)$ had definite TBM. At admission, most patients had history of fever $(88.3 \%)$, decreased consciousness $(74.6 \%)$, and seizures $(55.0 \%)$; the next most common signs and symptoms were weight loss $(37.6 \%)$, persistent cough $(33.7 \%)$, muscle weakness $(26.3 \%)$, and severe headache $(21.9 \%)$. These signs and symptoms had existed for $>5$ days before admission in $87.0 \%$ of patients (Table 1 ). We stratified manifestations by disease staging (Appendix Table 3).

In CSF analysis, most patients had pleocytosis (>10 cells $/ \mu \mathrm{L}, 76.8 \%)$, and lymphocytic predominance $(>50 \%, 81.8 \%)$, followed by a low CSF-toplasma glucose ratio $(<0.5,54.8 \%)$, elevated protein level (>100 mg/dL, 51.8\%), and hypoglycorrhachia ( $<40 \mathrm{mg} / \mathrm{dL}, 41.6 \%)$. M. tuberculosis susceptible to rifampin was identified by Xpert MTB/RIF assay in 48 $(34.3 \%)$ of 140 CSF samples and in $76(33.9 \%)$ of 224 non-CSF samples. In neuroimaging, most patients had basal meningeal enhancement (52.4\%), followed by hydrocephalus (41.2\%), tuberculoma (12.4\%), and infarct $(10.0 \%)$ (Table 2). Among 103 patients with hydrocephalus, $45(43 \%)$ received neurosurgical intervention: 44 (97.8\%) ventriculoperitoneal shunt and $1(2.2 \%)$ extraventricular drain.

For in-hospital complications, 106 (37.5\%) of the 283 patients had motor disorders, $37(13.1 \%)$ had neurodevelopmental delay, 19 (6.7\%) had epileptic 
seizures, 17 (6.0\%) had visual impairment, 12 (4.2\%) had hearing impairment, and 27 (9.5\%) had anti-TB drug-induced hepatotoxicity. Adjunctive oral corticosteroid was administered to $262(92.6 \%)$ of patients. In addition, 1 of the patients (a 6-month-old boy with stage II TBM) had severe acute respiratory syndrome coronavirus 2 coinfection (Appendix).

\section{In-Hospital Death}

Upon discharge, 231 (81.6\%) of 283 patients had recovered (with or without disability), 3 (1.1\%) had a persistent vegetative state, and $5(1.8 \%)$ were discharged against medical advice. The remaining 44 $(15.5 \%)$ died; median time to death was 7 days (interquartile range 3-13 days) after admission (Table 3 ).

We performed univariate (Appendix Table 4) and multivariate (Table 4) analyses of risk for inhospital death. In multivariate analysis, factors associated with increased risk were stage III TBM (aHR 5.96 [95\% CI 1.39-25.58]), hydrocephalus (aHR 2.32 [95\% CI 1.13-4.79]), male sex (aHR 2.10 [95\% CI 1.09-4.05]), low-income parents (aHR 2.59

\begin{tabular}{|c|c|c|c|c|c|c|}
\hline Characteristic & No.† & Value & No.† & Value & No.† & Value \\
\hline \multicolumn{7}{|l|}{ Sex } \\
\hline $\begin{array}{l}M \\
F\end{array}$ & $\begin{array}{l}283 \\
283\end{array}$ & $\begin{array}{l}150(53.0) \\
133(47.0)\end{array}$ & $\begin{array}{l}153 \\
153\end{array}$ & $\begin{array}{l}74(48.4) \\
79(51.6)\end{array}$ & $\begin{array}{l}130 \\
130\end{array}$ & $\begin{array}{l}76(58.5) \\
54(41.5)\end{array}$ \\
\hline \multicolumn{7}{|l|}{ Nutritional status $\ddagger$} \\
\hline Known BCG vaccination & 283 & $223(78.8)$ & 153 & $120(78.4)$ & 130 & $103(79.2)$ \\
\hline Known TB contact history & 283 & $73(25.8)$ & 153 & $36(23.5)$ & 130 & $37(28.5)$ \\
\hline Known HIV co-infection & 283 & $4(1.4)$ & 153 & $0(0.0)$ & 130 & $4(3.1)$ \\
\hline \multicolumn{7}{|l|}{ Motor function } \\
\hline $\begin{array}{l}\text { Hemiparesis } \\
\text { Quadriparesis }\end{array}$ & $\begin{array}{l}263 \\
263 \\
\end{array}$ & $\begin{array}{l}51(19.4) \\
95(36.1) \\
\end{array}$ & $\begin{array}{l}142 \\
142 \\
\end{array}$ & $\begin{array}{l}27(19.0) \\
59(41.5) \\
\end{array}$ & $\begin{array}{l}121 \\
121\end{array}$ & $\begin{array}{l}24(19.8) \\
36(29.8) \\
\end{array}$ \\
\hline Cranial nerve palsy & 277 & $48(17.3)$ & 149 & $31(20.8)$ & 128 & $17(13.3)$ \\
\hline Signs of upper motor neuron lesion & 264 & $188(71.2)$ & 143 & $93(65.0)$ & 121 & $95(78.5$ \\
\hline Signs of raised intracranial pressure & 283 & $47(16.6)$ & 153 & $29(19.0)$ & 130 & $18(13.8)$ \\
\hline \multicolumn{7}{|c|}{$\begin{array}{l}\text { *Values are no. (\%) or median (IQR) except as indicated. BCG, bacillus Calmette-Guérin; BFAZ, body mass index-for-age Z-score; GCS, Glasgow Coma } \\
\text { Scale; HFAZ, height-for-age Z-score; IQR, interquartile rage; TB, tuberculosis; TBM, tuberculous meningitis; WFAZ, weight-for-age Z-score. } \\
\text { †Number of total patients for whom data were available (denominator). } \\
\text { fln children }<5 \text { years of age, moderate malnutrition was defined as WFAZ or HFAZ } \geq-3 \text { but }<-2 \text { standard deviation (SD), and severe malnutrition as } \\
\text { WFAZ or HFAZ <-3 SD. In children aged } 5-14 \text { y, moderate malnutrition was defined as HFAZ or BFAZ } \geq-3 \text { but <-2 SD, and severe malnutrition as HFAZ } \\
\text { or BFAZ <-3 SD. } \\
\text { SDuration of symptoms before admission. } \\
\text { TDiagnostic certainty was categorized as definite TBM (microbiologically proven from CSF examination), probable TBM (diagnostic score of } \geq 10 \text { when } \\
\text { neuroimaging was unavailable or } \geq 12 \text { when neuroimaging was available), and possible TBM (diagnostic score of } 6-9 \text { when neuroimaging was } \\
\text { unavailable or } 6-11 \text { when neuroimaging was available) (18). } \\
\text { \#TBM staging was classified according to the modified British Medical Research Council grading system as stage I (GCS of } 15 \text { with no focal neurologic } \\
\text { signs), stage II (GCS } 11-14 \text { or } 15 \text { with focal neurologic signs), or stage III (GCS } \leq 10)(20) \text { ). }\end{array}$} \\
\hline
\end{tabular}


Table 2. Laboratory and radiographic findings at admission of children with tuberculous meningitis treated at Hasan Sadikin Hospital, Bandung, Indonesia, 2011-2020*

\begin{tabular}{|c|c|c|c|c|c|c|}
\hline \multirow[b]{2}{*}{ Characteristic } & \multicolumn{2}{|c|}{ Total patients } & \multicolumn{2}{|c|}{ Age $<5 y$} & \multicolumn{2}{|c|}{ Age 5-14 y } \\
\hline & No.† & Value & No.† & Value & No.† & Value \\
\hline \multicolumn{7}{|l|}{ CSF analysis, median (IQR) } \\
\hline Leukocytes, cells $/ \mu \mathrm{L}$ & 276 & $44(11-109)$ & 149 & $56(14-117)$ & 127 & $40(8-95)$ \\
\hline Protein, $\mathrm{mg} / \mathrm{dL}$ & 276 & $107(60-239)$ & 151 & $103(68-234)$ & 125 & $120(46-248)$ \\
\hline $\mathrm{MN}, \%$ & 275 & $83(60-96)$ & 151 & $81(60-95)$ & 124 & $86(64-98)$ \\
\hline PMN, \% & 275 & $15(4-37)$ & 151 & $18(5-40)$ & 124 & $12(0.2-36)$ \\
\hline Glucose, mg/dL & 269 & $47(25-66)$ & 150 & $42(20-67)$ & 119 & $52(34-66)$ \\
\hline CSF-to-plasma glucose ratio, median (IQR) & 241 & $0.4(0.2-0.6)$ & 140 & $0.4(0.2-0.6)$ & 101 & $0.5(0.3-0.6)$ \\
\hline \multicolumn{7}{|l|}{ Cerebral imaging $\ddagger$} \\
\hline Hydrocephalus & 250 & $103(41.2)$ & 136 & $64(47.1)$ & 114 & $39(34.2)$ \\
\hline Basal meningeal enhancement & 250 & $131(52.4)$ & 136 & $74(54.4)$ & 114 & $57(50.0)$ \\
\hline Infarct & 250 & $25(10.0)$ & 136 & $12(8.8)$ & 114 & $13(11.4)$ \\
\hline Tuberculoma & 250 & $31(12.4)$ & 136 & $17(12.5)$ & 114 & $14(12.3)$ \\
\hline \multicolumn{7}{|l|}{ Chest radiography } \\
\hline Miliary TB & 281 & $19(6.8)$ & 152 & $10(6.6)$ & 129 & $9(7.0)$ \\
\hline Other signs of active TB & 281 & $128(45.6)$ & 152 & $66(43.4)$ & 129 & $62(48.1)$ \\
\hline TST positive§ & 283 & $64(22.6)$ & 153 & $37(24.2)$ & 130 & $27(20.8)$ \\
\hline M. tuberculosis cultured from any source & 267 & $26(9.7)$ & 147 & $15(10.2)$ & 120 & $11(9.2)$ \\
\hline \multicolumn{7}{|l|}{ AFB smear microscopy } \\
\hline Positive from CSF & 272 & $6(2.2)$ & 149 & $4(2.7)$ & 123 & $2(1.6)$ \\
\hline Positive from any non-CSF sample\# & 282 & $49(17.4)$ & 152 & $23(15.1)$ & 130 & $26(20.0)$ \\
\hline \multicolumn{7}{|l|}{ Xpert MTB/RIF testing ${ }^{* *}$} \\
\hline Positive from CSF & 140 & $48(34.3)$ & 77 & $24(31.2)$ & 63 & $24(38.1)$ \\
\hline Positive from gastric lavage & 212 & $71(33.5)$ & 120 & $43(35.8)$ & 92 & $28(30.4)$ \\
\hline Positive from sputum & 12 & $5(41.7)$ & 2 & 0 & 10 & $5(50.0)$ \\
\hline
\end{tabular}

*Values are no. (\%) or median (IQR) except as indicated. AFB, acid-fast bacilli; CSF, cerebrospinal fluid; IQR, interquartile rage; MN, mononuclear cells;

PMN, polymorphonuclear cells; TB, tuberculosis; TST, tuberculin skin test.

†Number of total patients for whom data were available (denominator).

fCerebral imaging results were obtained mostly from noncontrast brain computed tomography scan, or from magnetic resonance imaging, where available.

§The median size of induration (minimum-maximum range) in patients with a positive TST result was 12 (10-30) mm and in patients with a negative TST result was $0(0-8) \mathrm{mm}$.

ПCulture of M. tuberculosis from CSF is rarely performed in our setting, mostly because of the limited CSF volume available from lumbar puncture. From our experience, most of the non-CSF specimens were obtained from gastric lavage, and some specimens were obtained from sputum, but our data could not further specify the type of specimens used. Mycobacterial culture were mostly performed on solid media; the use of liquid culture media (MGIT,

BACTEC) has only begun in recent years.

\#We could not further specify the types of non-CSF specimens used for AFB smear microscopy.

${ }^{* *}$ Data on Xpert MTB/RIF testing results have only been available since 2013.

[95\% CI 1.06-6.31]), seizures on admission (aHR 1.96 [95\% CI 1.01-3.82]), and unknown BCG vaccination (aHR 1.97 [95\% CI 1.03-3.76]). Among children $<5$ years of age, known history of TB contact was associated with an increased risk for in-hospital death (aHR 2.42 [95\% CI 1.06-5.50]), adjusted for age, sex, and TBM staging. We charted KaplanMeier curves for several risk groups for in-hospital death (Figure).

\section{Postdischarge Death}

After the 12-month follow-up, 272 (96.1\%) of 283 patients were evaluated for treatment outcomes, and 11 $(3.9 \%)$ in ongoing treatment who started taking anti-TB drugs in late 2020 were excluded from further analysis. Among the 272 patients, 91 (33.5\%) completed treatment, $1(0.4 \%)$ was LTFU, and $62(22.8 \%)$ died, including 18 (6.6\%) who died after discharge; $118(43.4 \%)$ had unknown outcomes (Table 3$)$.

We performed univariate (Appendix Table 5) and multivariate (Table 5) analyses of odds for postdischarge death. Multivariate analysis identified that patients with unknown BCG vaccination status (aOR 5.38 [95\% CI 1.07-27.07]) and those with clinical findings during hospitalization such as hydrocephalus (aOR 18.97 [95\% CI 2.68-134.38]) and tuberculoma (aOR 8.78 [95\% CI 1.10-70.39]) had increased odds of postdischarge death. Among patients with hydrocephalus, the absence of neurosurgical intervention was associated with increased odds of postdischarge death (aOR 11.06 [95\% CI 1.61-76.12]), adjusted for age, sex, and TBM staging.

\section{Neurologic Sequelae}

Among 91 survivors who completed treatment, 58 $(63.7 \%)$ had good recovery without neurologic sequelae and 33 (36.3\%) had severe neurologic sequelae (Table 3). Of patients with severe neurologic sequelae, $22(66.7 \%)$ had motor disorders, $9(27.3 \%)$ had epileptic seizures, 7 (21.2\%) had neurodevelopmental delay, 3 (9.1\%) had visual impairment, and 3 (9.1\%) had hearing impairment. Neurologic sequelae were 
observed in $23 \%$ of patients diagnosed with TBM at stage I, $31 \%$ at stage II, and $58 \%$ at stage III.

We performed univariate (Appendix Table 6) and multivariate (Table 6) analyses of odds for neurologic sequelae. In multivariate analysis, factors associated with higher odds of severe neurologic sequelae were baseline temperature $\geq 38^{\circ} \mathrm{C}$ (aOR 6.68 [95\% CI 1.55-28.85]), stage III TBM (aOR 5.65 [95\% CI 1.21-26.43]), and motor deficits at baseline (aOR 3.64 [95\% CI 1.19-11.16]).

\section{Discussion}

We present important information from Indonesia about the high rates of neurologic sequelae and death in children with TBM, even when standard therapy has been provided. In TBM, treatment response is often judged by early morbidity, mortality, and relapse rates (21). Our overall case-fatality rate for childhood TBM $(22.8 \%)$ is within the global estimates reported in a recent meta-analysis $(19.3 \%$ [95\% CI $14.0 \%-26.1 \%]$ ) (2) but is lower than that reported in the same setting during 2007-2010 (34.4\%) (14). The high proportion of unknown treatment outcomes in this study ( $43 \%$ ) is unfortunate but comparable to a previous report in our hospital during 2007-2010 (45\%), even after phone calls and home visits had been made (14). Considering the increased likelihood of death in patients with unknown outcomes after hospital discharge, the case-fatality rate recorded is probably an underestimate.

A diagnosis of TBM alone has been associated with an increased risk for childhood death compared with other types of TB (22), and this risk may be exacerbated by specific risk factors identified in this study. TBM diagnosis in stage II or III, hydrocephalus, and seizures are not surprising risk factors for death because they reflect more advanced disease. Neurosurgical complications (e.g., shunt blockage or infections) may have contributed to poor outcomes, but we believe the effect was minimal because the postdischarge death rate was significantly reduced with neurosurgery. The association of tuberculoma on baseline CT with postdischarge death might be related to a paradoxical worsening of tuberculomas during treatment (23). For male sex and low-income parents, their associations with in-hospital death are unclear but could be related to biologic factors (particularly for sex differences) or largely attributed to socioeconomic and cultural determinants (24).

This study confirms that TBM mainly affects young children (8), illustrated by $54 \%$ of our patients being $<5$ years of age. The high proportions of altered consciousness and seizures at admission suggest that these symptoms are the main reasons for clinicians to suspect childhood TBM. This finding raises important issues about training of healthcare

\begin{tabular}{|c|c|c|c|c|}
\hline Variable & Total & Stage I† & Stage II† & Stage III† \\
\hline \multicolumn{5}{|l|}{ Outcome of hospitalization $\ddagger$} \\
\hline Cases, no. & 283 & 57 & 131 & 95 \\
\hline Recovered & $231(81.6)$ & $54(94.7)$ & $111(84.7)$ & $66(69.5)$ \\
\hline Not recovered & $8(2.8)$ & $1(1.8)$ & $5(3.8)$ & $2(2.1)$ \\
\hline Died & $44(15.5)$ & $2(3.5) \S$ & $15(11.5)$ & $27(28.4)$ \\
\hline Length of hospital stay, $d$, median (IQR) & $10(7-17)$ & $9(7-14)$ & $10(7-14)$ & $15(8-25)$ \\
\hline Time to death, $\mathrm{d}$, median (IQR) & $7(3-13)$ & $(4-14) \pi$ & $6(2-8)$ & $8(3-16)$ \\
\hline \multicolumn{5}{|l|}{ Outcome at treatment completion $\#$} \\
\hline Cases, no. & 272 & 56 & 122 & 94 \\
\hline Completed treatment & $91(33.5)$ & $22(39.3)$ & $45(36.9)$ & $24(25.5)$ \\
\hline Without neurologic sequelae ${ }^{\star *}$ & $58(63.7)$ & $17(77.3)$ & $31(68.9)$ & $10(41.7)$ \\
\hline With neurologic sequelae** & $33(36.3)$ & $5(22.7)$ & $14(31.1)$ & $14(58.3)$ \\
\hline Died & $62(22.8)$ & $2(3.6)$ & $22(18.0)$ & $38(40.4)$ \\
\hline Died after hospital discharge & $18(6.6)$ & $0(0.0)$ & $7(5.7)$ & $11(11.7)$ \\
\hline Lost to follow-up & $1(0.4)$ & $0(0.0)$ & $1(0.8)$ & $0(0.0)$ \\
\hline Unknown treatment outcome & $118(43.4)$ & $32(57.1)$ & $54(44.3)$ & $32(34.0)$ \\
\hline
\end{tabular}

*Values are no. (\%) except as indicated. IQR, interquartile rage.

†Stage I was defined as Glasgow Coma Scale (GCS) of 15 with no focal neurologic signs, stage II as GCS of 11-14 or 15 with focal neurologic signs, and stage III as GCS $\leq 10(20)$.

fOn hospital discharge, recovering patients were those who had clinical improvement (with or without disability), whereas non-recovering patients were those who had persistent vegetative state or discharged against medical advice. Treatment completion included patients who completed 12 mo of TBM therapy. Lost to follow-up included patients who stopped treatment for two consecutive months or more. Unknown treatment outcome included patients who were transferred back to regional public hospitals or community health clinics for follow-up after discharge. Neurologic sequelae were defined as any motor, hearing, visual, or neurodevelopmental impairment that appeared during the illness and persisted through treatment completion.

$\S$ The causes of death in two patients with stage I TBM were hospital acquired pneumonia + thalassemia major $(n=1)$, and intracranial metastases of Burkitt lymphoma + increased intracranial pressure $(n=1)$.

TMinimum-maximum range.

\#Excluding 11 patients who were still in ongoing treatment.

${ }^{* *}$ Percentages were calculated only in patients who completed 12 mo of treatment. 
Table 4. Multivariate Cox proportional-hazards regression model for factors associated with in-hospital death in children treated for TBM at Hasan Sadikin Hospital, Bandung, Indonesia, 2011-2020*

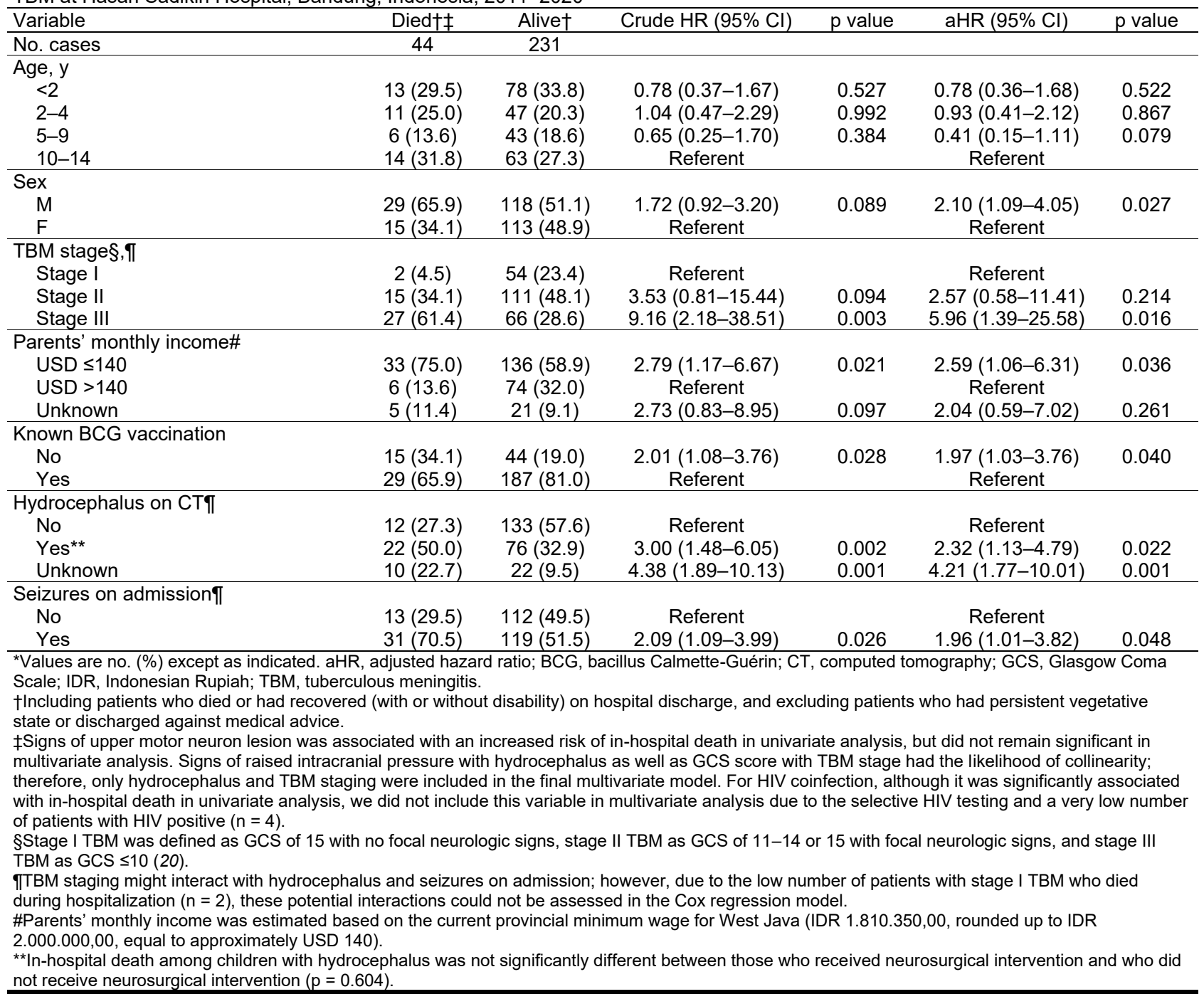

providers to improve their ability to recognize and diagnose the disease (25). In addition, increasing community awareness of the signs and symptoms of TBM by including enhanced messaging in existing TB advocacy materials has the potential to improve early recognition of childhood TBM (25).

The difficulty of early diagnosis is confirmed by the fact that nearly $80 \%$ of our patients had stage II or III TBM at admission. This high proportion of patients with advanced disease at admission is supported by various studies from high TB incidence countries in Asia and Africa $(11,14,26,27)$, and only slightly reduced in low TB incidence countries in Europe, where $66 \%$ of the patients have stage II or III TBM at admission (28). In many cases, nonspecific symptoms such as fever, headache, and vomiting are often wrongly interpreted, and other systemic symp- toms such as cough, weight loss, and night sweats may be suggestive of TB but are also nonspecific (18). The high risk for death in patients with unknown BCG vaccination status highlights the importance of better TB prevention. In young children, BCG vaccination has consistently shown protection against miliary TB and TBM (29-31) for $\geq 10$ years after vaccination (29). The global shortage of BCG vaccine since 2013, particularly in countries where it was procured through UNICEF (32), has led to an alarming increase in the number of hospital admissions for childhood TBM (33). In Indonesia, where BCG vaccine is recommended at birth for all infants and annual coverage has been an estimated $\approx 90 \%$ since 2011 (34), this shortage has also been experienced, although the vaccine supply depends largely on domestic production by Biofarma, a state-owned vaccine manufacturer 
(32). In addition, among children with prolonged exposure to $M$. tuberculosis, protection with BCG vaccination alone is unlikely to be sufficient. Without early initiation of preventive therapy, the risk for TB disease development among exposed young children and infants is very high (35), but data on preventive treatment in our patients with known TB contact history were unavailable. Taken together, aside from improving BCG vaccination coverage, it is important to reduce TB transmission in children through contact investigation, coupled with preventive therapy among exposed children.

Neurologic sequelae occurred mostly in our patients who had stage III TBM at admission (58\%), a higher rate than for those in stage I (23\%) and II (31\%). A meta-analysis in children with TBM confirms this upward trend with pooled estimates of $27 \%$ in stage I, $41 \%$ in stage II, and $70 \%$ in stage III (2). Recent studies also reported an increase in neurologic sequelae among children with stage II or III TBM $(36,37)$. In

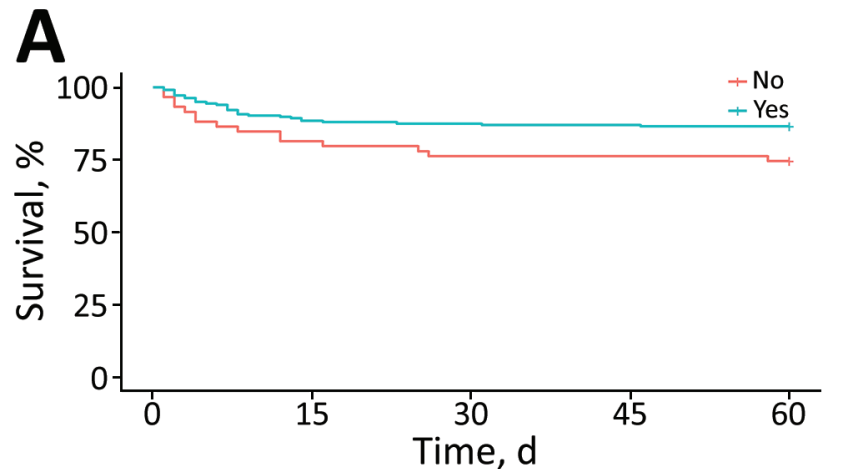

No. at risk

$\begin{array}{cccccc}\text { No } & 59 & 48 & 45 & 45 & 44 \\ \text { Yes } & 216 & 191 & 189 & 188 & 187\end{array}$

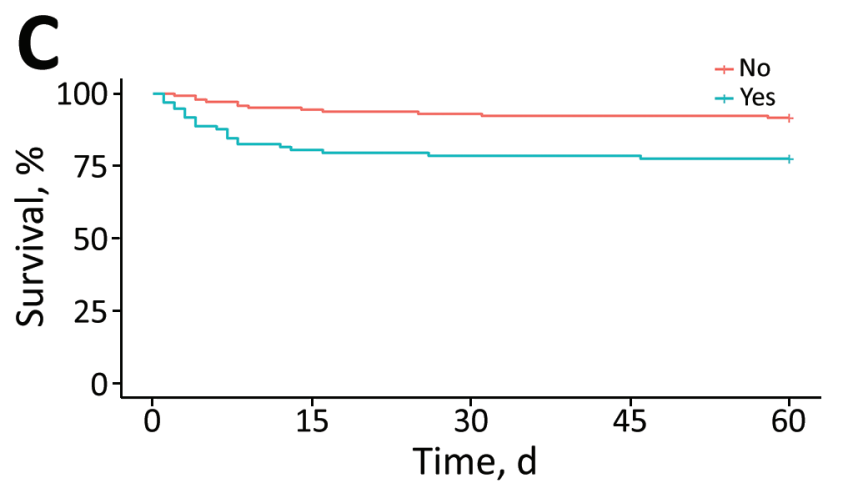

No. at risk

$\begin{array}{rcccr}\text { No } 145 & 137 & 135 & 134 & 133 \\ \text { Yes } 98 & 79 & 77 & 77 & 76\end{array}$

children in South Africa with TBM, severe neurologic sequelae and death were significantly associated with cerebral infarctions (11); we did not find this association in our study. A high proportion of patients had hemiparesis or quadriparesis at admission in this study $(55 \%)$, comparable to that reported in South Africa $(62.1 \%)(11)$, but few patients had cerebral infarcts on brain CT (10\%). This finding is difficult to explain but is likely attributable to the low sensitivity of early infarct detection with noncontrast CT as commonly used in the study.

Given the substantial levels of neurologic sequelae and death associated with childhood TBM, the current standard care for childhood TBM clearly remains suboptimal. New diagnostic strategies should be tested in future clinical trials because of the poor sensitivity, specificity, or both of available laboratory and clinical diagnostic tools (38). For TBM treatment, future research should explore the use of intensified antimicrobial therapy that contains high-dose

B

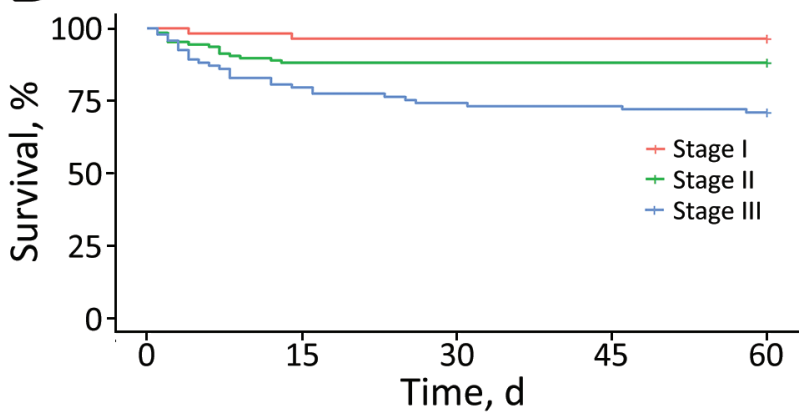

No. at risk

\begin{tabular}{|c|c|c|c|c|}
\hline Stage | 56 & 54 & 54 & 54 & 54 \\
\hline Stage II 126 & 111 & 111 & 111 & 111 \\
\hline Stage III 93 & 74 & 69 & 68 & 66 \\
\hline
\end{tabular}

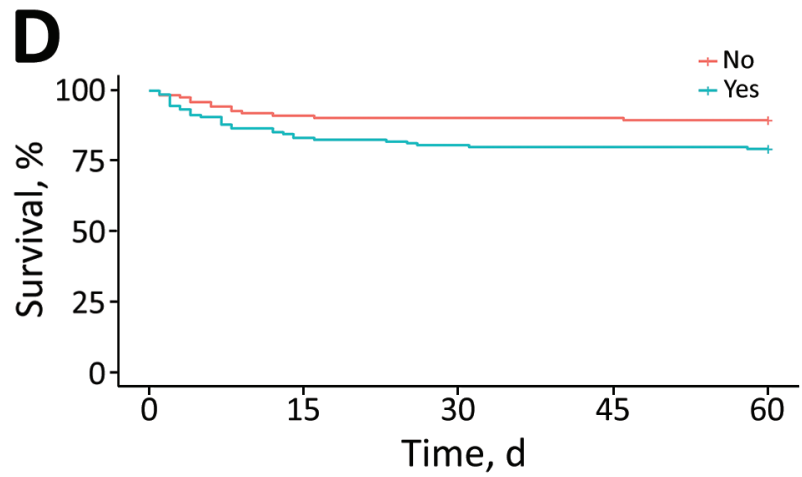

$\begin{array}{lllll}\text { No. at risk } & & & & \\ \text { No } 125 & 114 & 113 & 113 & 112 \\ \text { Yes } 150 & 125 & 121 & 120 & 119\end{array}$

Figure. Survival curves for in-hospital death in children treated for tuberculous meningitis at Hasan Sadikin Hospital, Bandung, Indonesia, 2011-2020. A) Known bacillus Calmette-Guérin (BCG) vaccination status (yes/no); B) tuberculous meningitis stage (I-III); C) radiographic evidence of hydrocephalus (yes/no); D) presence of seizures at hospital admission (yes/no). 
rifampin and other anti-TB drugs with better CSF penetration and bactericidal activity (39). On the basis of observational data among children in South Africa, a 6-month intensified TBM treatment regimen with isoniazid, rifampin, and ethionamide at $20 \mathrm{mg} / \mathrm{kg} /$ day and pyrazinamide at $40 \mathrm{mg} / \mathrm{kg} /$ day was reported to be safe and effective, with lower case-fatality rates ranging from $4 \%-14 \%(11,12,40)$. This short-course, high-dose therapy has recently been added by WHO as an alternative treatment option for childhood TBM (41). Suboptimal plasma and CSF concentrations with standard doses of oral rifampin at $10-20 \mathrm{mg} / \mathrm{kg} /$ day in children with TBM have also been reported in recent pharmacokinetic studies $(42,43)$, advocating the use of higher rifampin doses with further efficacy and safety evaluations.

Minimizing damaging immunologic responses leading to neurologic complications by using antiinflammatory drugs such as aspirin, thalidomide, and specific tumor necrosis factor a antibodies (e.g., infliximab) also warrants further investigations
(10,44-46), particularly for paradoxical TBM reactions and potentially also for TBM in general. There is no evidence that corticosteroids (the mainstay of host-directed therapy) reduce neurologic sequelae although they do improve the TBM survival rate (47). Therefore, optimization of anti-TB drug dosing and consideration of immunomodulatory therapy beyond corticosteroids are required to improve childhood TBM treatment outcomes $(9,46)$. Moreover, understanding the disease pathogenesis pathways of childhood TBM, particularly in the cerebral inflammatory response, is likely to offer valuable insights into potential targets for new treatment interventions $(48,49)$.

The main limitation of our study is that, although most of the essential information recommended for TBM research was available (50), the retrospective nature of the study did not provide us with complete records on all key variables, especially longer-term outcome. Our dataset did not contain information on the drug-susceptibility pattern of the source case and was

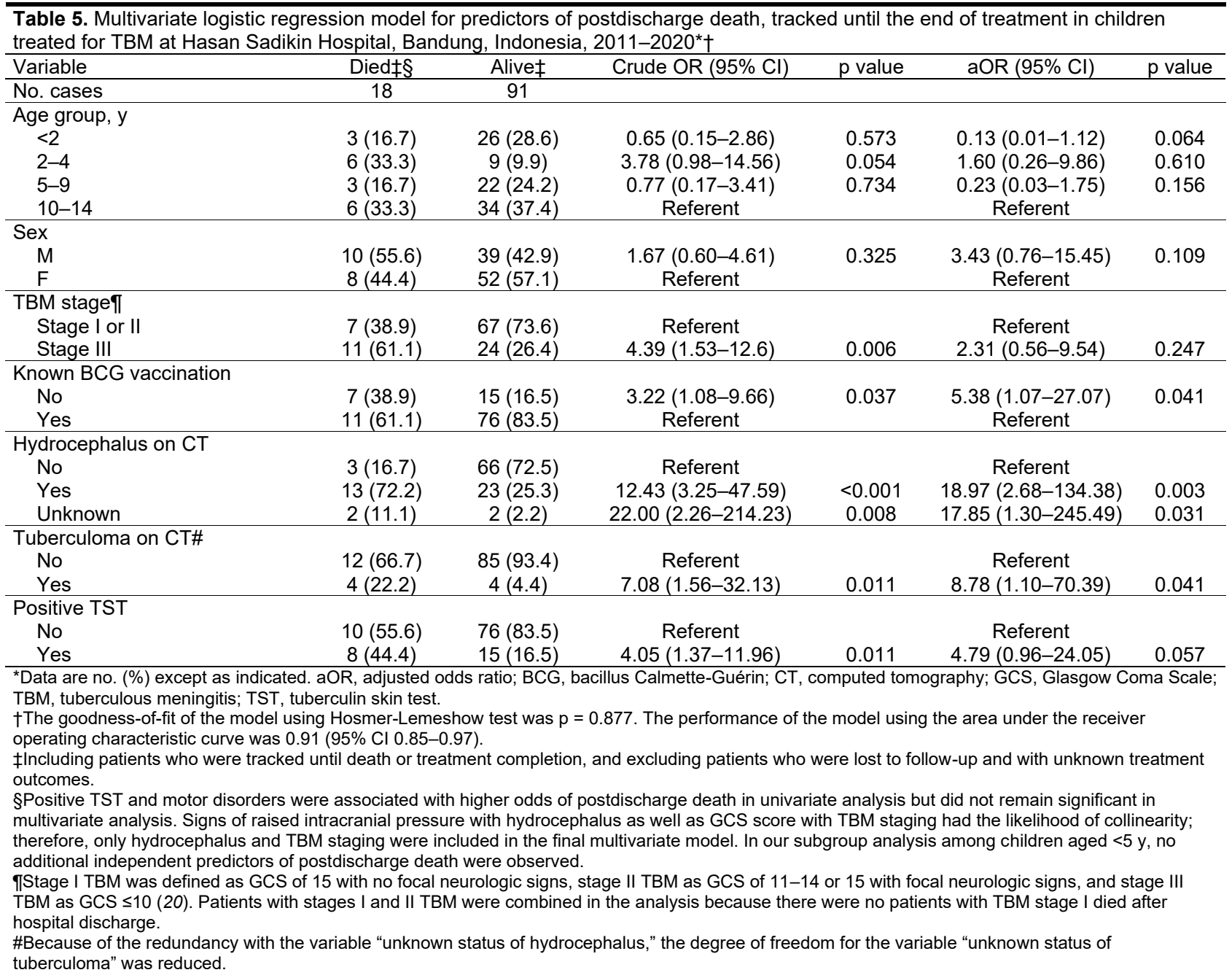


Childhood TB Meningitis, Bandung, Indonesia

Table 6. Multivariate logistic regression model for predictors of severe neurologic sequelae at treatment completion in children treated for TBM at Hasan Sadikin Hospital, Bandung, Indonesia, 2011-2020*†

\begin{tabular}{|c|c|c|c|c|c|c|}
\hline \multirow[b]{2}{*}{ Variable } & \multicolumn{2}{|c|}{ Neurologic sequelae } & \multirow[b]{2}{*}{ Crude OR $(95 \% \mathrm{Cl})$} & \multirow[b]{2}{*}{$p$ value } & \multirow[b]{2}{*}{ aOR $(95 \% \mathrm{Cl})$} & \multirow[b]{2}{*}{$p$ value } \\
\hline & Yes $\ddagger \S$ & Noł & & & & \\
\hline Cases, no. & 33 & 58 & & & & \\
\hline \multicolumn{7}{|l|}{ Age group, y } \\
\hline$<2$ & $13(39.4)$ & $13(22.4)$ & $2.78(0.94-8.20)$ & 0.064 & $2.59(0.67-10.00)$ & 0.166 \\
\hline $2-4$ & $2(6.1)$ & $7(12.1)$ & $0.79(0.14-4.55)$ & 0.795 & $0.97(0.13-7.28)$ & 0.974 \\
\hline $5-9$ & $9(27.3)$ & $13(22.4)$ & $1.92(0.61-6.02)$ & 0.261 & $1.32(0.34-5.07)$ & 0.684 \\
\hline $10-14$ & $9(27.3)$ & $25(43.1)$ & Referent & & Referent & \\
\hline \multicolumn{7}{|l|}{ Sex } \\
\hline$M$ & $12(36.4)$ & $27(46.6)$ & $0.66(0.27-1.58)$ & 0.346 & & 0.191 \\
\hline $\mathrm{F}$ & $21(63.6)$ & $31(53.4)$ & Referent & & Referent & \\
\hline \multicolumn{7}{|l|}{ TBM stageף } \\
\hline Stage I & $5(15.2)$ & $17(29.3)$ & Referent & & Referent & \\
\hline Stage II & $14(42.4)$ & $31(53.4)$ & $1.53(0.47-5.00)$ & 0.476 & $1.83(0.43-7.75)$ & 0.410 \\
\hline Stage III & $14(42.4)$ & $10(17.2)$ & $4.76(1.32-17$. & & $5.65(1.21-2$ & 0.028 \\
\hline \multicolumn{7}{|c|}{ Baseline temperature $\geq 38^{\circ} \mathrm{C}$} \\
\hline No & $23(69.7)$ & $53(91.4)$ & Referent & & Referent & \\
\hline Yes & $10(30.3)$ & $5(8.6)$ & $4.61(1.42-14.99)$ & 0.011 & $6.68(1.55-28.85)$ & 0.011 \\
\hline \multicolumn{7}{|c|}{ Motor deficit at baseline } \\
\hline No & $8(24.2)$ & $27(46.6)$ & Referent & & Referent & \\
\hline Yes & $24(72.7)$ & $23(39.7)$ & 3.52 (1.33-9.33) & 0.011 & $3.64(1.19-11.16)$ & 0.024 \\
\hline Unknown & $1(3.0)$ & $8(13.8)$ & $0.42(0.05-3.90)$ & 0.447 & $0.39(0.03-4.58)$ & 0.452 \\
\hline \multicolumn{7}{|c|}{$\begin{array}{l}\text { *Values are no. (\%) except as indicated. aOR, adjusted odds ratio; TB, tuberculosis; TBM, tuberculous meningitis. } \\
\text { †The goodness-of-fit of the model using Hosmer-Lemeshow test was } p=0.473 \text {. The performance of the model using the area under the receiver } \\
\text { operating characteristic curve was } 0.80(95 \% \mathrm{Cl} 0.70-0.90) \text {. } \\
\text { flncluding patients who were tracked until treatment completion, and excluding those who died, who were lost to follow-up and with unknown treatment } \\
\text { outcomes (which represents a large percentage of the cohort }(\mathrm{n}=118,43.3 \%) \text {. Neurologic sequelae were defined as any motor, hearing, visual or } \\
\text { neurodevelopmental impairment that appeared during the illness and persisted through treatment completion. } \\
\text { §Suggestive TB through chest radiography was associated with an increased odd of neurologic sequelae in univariate analysis but did not remain } \\
\text { significant in multivariate analysis. In our subgroup analysis among children aged }<5 \mathrm{y} \text {, no additional independent predictors for neurologic sequelae } \\
\text { were found. } \\
\text { TStage I TBM was defined as Glasgow Coma Scale (GCS) of } 15 \text { with no focal neurologic signs, stage II TBM as GCS of } 11-14 \text { or } 15 \text { with focal neurologic } \\
\text { signs, and stage III TBM as GCS } \leq 10(20) \text {. }\end{array}$} \\
\hline
\end{tabular}

unable to reliably distinguish a contact history with an infectious drug-susceptible or drug-resistant TB case. This limitation may have led to underdiagnosis of drugresistant TB disease, resulting in inappropriate antimicrobial therapy that may have contributed to poor outcomes. However, drug-resistance rates are not known to be high in the study population, an estimated $2.4 \%$ of multidrug-resistant TB among new cases in Indonesia (1), limiting the likely effect of inappropriate treatment of drug-resistant disease. In addition, the frequency of total neurologic sequelae at treatment completion might be underestimated in this study, given that mild to moderate sequelae were not tested or recorded in the database. Despite its limitations, this study provides one of the largest child TBM cohorts ever described globally outside of South Africa (11), and includes a wide range of variables in the analysis.

In conclusion, childhood TBM in Indonesia causes substantial neurologic sequelae and death, despite standard treatment. Several predictors of inhospital death, postdischarge death, and neurologic sequelae have been identified for further development of early and tailored interventions to optimize care in this population. This study emphasizes the importance of improved early diagnosis, better TB prevention beyond BCG vaccination, and optimizing
TBM management strategies, including antimicrobial and supportive therapy.

\section{Acknowledgments}

We thank the director of Hasan Sadikin Hospital and head of the Department of Child Health of Hasan Sadikin Hospital for accommodating the study. We also thank Raisa Moeis for helping with data checking.

This work was supported by the Academic Leadership Grant of the Universitas Padjadjaran (grant no. 4851/ UN6.C/LT/2018) awarded to H.M.N. The funding organization was in no way involved in study design or conception, writing or reviewing of the manuscript, and decision to submit the manuscript for publication.

H.M.N. was the principal investigator. H.M.N., R.R., N.A.R., and F.G. contributed to conception and design of the study. H.M.N. contributed to data collection, whereas H.M.N. and F.G. contributed to data cleaning. F.G. performed data analysis and created tables and figures. H.M.N., F.G., N.A.R., D.A.W., S.S., B.J.M., J.S., J.W.C.A., and R.R. interpreted the results. F.G. drafted the manuscript under the supervision of H.M.N. and J.W.C.A. All authors critically revised the manuscript for important intellectual content and approved the final version of the manuscript before submission for publication. 


\section{About the Author}

Dr. Nataprawira is a professor of pediatrics at the Universitas Padjadjaran and Hasan Sadikin Hospital. Her primary research interests include pediatric respirology, particularly tuberculosis. Mr. Gafar is a PhD student at the University of Groningen. His primary research interests include the epidemiology and pharmacotherapy of pediatric tuberculosis.

\section{References}

1. World Health Organization. Global tuberculosis report 2020. 2020 [cited 2021 Dec 28]. https:/ / www.who.int/ publications/i/item/9789240013131

2. Chiang SS, Khan FA, Milstein MB, Tolman AW, Benedetti A, Starke JR, et al. Treatment outcomes of childhood tuberculous meningitis: a systematic review and meta-analysis. Lancet Infect Dis. 2014;14:947-57. https://doi.org/10.1016/S1473-3099(14)70852-7

3. Marais BJ, Gie RP, Schaaf HS, Hesseling AC, Obihara CC, Starke JJ, et al. The natural history of childhood intrathoracic tuberculosis - a critical review of the pre-chemotherapy literature. Int J Tuberc Lung Dis. 2004;8:392-402.

4. García-Basteiro AL, Schaaf HS, Diel R, Migliori GB. Adolescents and young adults: a neglected population group for tuberculosis surveillance. Eur Respir J. 2018;51:1800176. https://doi.org/10.1183/13993003.00176-2018

5. Marais BJ, Amanullah F, Gupta A, Becerra MC, Snow K, Ngadaya E, et al. Tuberculosis in children, adolescents, and women. Lancet Respir Med. 2020;8:335-7. https:/ / doi.org/10.1016/S2213-2600(20)30077-1

6. World Health Organization. Roadmap towards ending TB in children and adolescents, second edition [cited 2021 Dec 28]. https:/ / apps.who.int/iris/bitstream/ handle/10665/274374/9789241514668-eng.pdf

7. Wilkinson RJ, Rohlwink U, Misra UK, van Crevel R, Mai NTH, Dooley KE, et al.; Tuberculous Meningitis International Research Consortium. Tuberculous meningitis. Nat Rev Neurol. 2017;13:581-98. https:// doi.org/10.1038/nrneurol.2017.120

8. van Toorn $\mathrm{R}$, Solomons R. Update on the diagnosis and management of tuberculous meningitis in children. Semin Pediatr Neurol. 2014;21:12-8. https:/ / doi.org/10.1016/ j.spen.2014.01.006

9. Hill J, Marais B. Improved treatment for children with tuberculous meningitis: acting on what we know. Arch Dis Child. 2022;107:68-9. https://doi.org/10.1136/ archdischild-2021-322660

10. Huynh J, Thwaites G, Marais BJ, Schaaf HS. Tuberculosis treatment in children: the changing landscape. Paediatr Respir Rev. 2020;36:33-43.

11. van Well GTJ, Paes BF, Terwee CB, Springer P, Roord JJ, Donald PR, et al. Twenty years of pediatric tuberculous meningitis: a retrospective cohort study in the western cape of South Africa. Pediatrics. 2009;123:e1-8. https://doi.org/10.1542/ peds.2008-1353

12. van Toorn R, Schaaf HS, Laubscher JA, van Elsland SL, Donald PR, Schoeman JF. Short intensified treatment in children with drug-susceptible tuberculous meningitis. Pediatr Infect Dis J. 2014;33:248-52. https:/ / doi.org/10.1097/ INF.0000000000000065

13. Yaramiş A, Gurkan F, Elevli M, Söker M, Haspolat K, Kirbaş G, et al. Central nervous system tuberculosis in children: a review of 214 cases. Pediatrics. 1998;102:E49. https://doi.org/10.1542/peds.102.5.e49
14. Nataprawira HM, Ruslianti V, Solek P, Hawani D, Milanti M, Anggraeni R, et al. Outcome of tuberculous meningitis in children: the first comprehensive retrospective cohort study in Indonesia. Int J Tuberc Lung Dis. 2016;20:909-14. https://doi.org/10.5588/ijtld.15.0555

15. Faried A, Ramdan A, Arifin MZ, Nataprawira HM. Characteristics and surgical outcomes of tuberculous meningitis and of tuberculous spondylitis in pediatric patients at Dr. Hasan Sadikin Hospital, Bandung: a single center experience. Interdiscip Neurosurg Adv Tech Case Manag. 2018;11:37-40. https://doi.org/10.1016/ j.inat.2017.09.008

16. Faried A, Putra SPS, Suradji EW, Trianto, Akbar RR, Nugraheni NK, et al. Characteristics and outcomes of pediatric tuberculous meningitis patients with complicated by hydrocephalus with or without tuberculoma at Regional Public Hospital Teluk Bintuni, West Papua, Indonesia. Interdiscip Neurosurg. 2020;19:100609. https:/ / doi.org/ 10.1016/j.inat.2019.100609

17. Rahajoe NN, Nawas A, Setyanto DB, Kaswandani N, Triasih R, Indawati $\mathrm{W}$, et al. Buku petunjuk teknis manajemen dan tatalaksana TB anak [National guideline on the management of tuberculosis in children]. Ministry of Health of the Republic of Indonesia. Jakarta (Indonesia): Ministry of Health of the Republic of Indonesia; 2016.

18. Marais S, Thwaites G, Schoeman JF, Török ME, Misra UK, Prasad K, et al. Tuberculous meningitis: a uniform case definition for use in clinical research. Lancet Infect Dis. 2010;10:803-12. https://doi.org/10.1016/ S1473-3099(10)70138-9

19. World Health Organization. Guidance for national tuberculosis programmes on the management of tuberculosis in children (2nd edition). World Health Organization; 2014 [cited 2022 Feb 5]. https:/ / www.who.int/publications/i/ item/9789241548748

20. Thwaites GE, Nguyen DB, Nguyen HD, Hoang TQ, Do TTO, Nguyen TCT, et al. Dexamethasone for the treatment of tuberculous meningitis in adolescents and adults. N Engl J Med. 2004;351:1741-51. https:/ / doi.org/ 10.1056/NEJMoa040573

21. Donald PR. The chemotherapy of tuberculous meningitis in children and adults. Tuberculosis (Edinb). 2010;90:375-92. https://doi.org/10.1016/j.tube.2010.07.003

22. Gafar F, Van't Boveneind-Vrubleuskaya N, Akkerman OW, Wilffert B, Alffenaar JC. Nationwide analysis of treatment outcomes in children and adolescents routinely treated for tuberculosis in the Netherlands. Eur Respir J. 2019;54:1901402. https:/ / doi.org/10.1183/ 13993003.01402-2019

23. Kalita J, Prasad S, Misra UK. Predictors of paradoxical tuberculoma in tuberculous meningitis. Int J Tuberc Lung Dis. 2014;18:486-91. https://doi.org/10.5588/ijtld.13.0556

24. Chidambaram V, Tun NL, Majella MG, Ruelas Castillo J, Ayeh SK, Kumar A, et al. Male sex is associated with worse microbiological and clinical outcomes following tuberculosis treatment: a retrospective cohort study, a systematic review of the literature, and meta-analysis. Clin Infect Dis. 2021;73: 1580-8. https://doi.org/10.1093/cid/ciab527

25. Basu Roy R, Bakeera-Kitaka S, Chabala C, Gibb DM, Huynh J, Mujuru H, et al. Defeating paediatric tuberculous meningitis: applying the WHO "defeating meningitis by 2030: global roadmap." Microorganisms. 2021;9:857. https:/ / doi.org/10.3390/microorganisms9040857

26. Maree F, Hesseling AC, Schaaf HS, Marais BJ, Beyers N, van Helden $\mathrm{P}$, et al. Absence of an association between Mycobacterium tuberculosis genotype and clinical 
features in children with tuberculous meningitis. Pediatr Infect Dis J. 2007;26:13-8. https://doi.org/10.1097/ 01.inf.0000247044.05140.c7

27. Rohlwink UK, Donald K, Gavine B, Padayachy L, Wilmshurst JM, Fieggen GA, et al. Clinical characteristics and neurodevelopmental outcomes of children with tuberculous meningitis and hydrocephalus. Dev Med Child Neurol. 2016;58:461-8. https:/ / doi.org/10.1111/dmcn.13054

28. Basu Roy R, Thee S, Blázquez-Gamero D, Falcón-Neyra L, Neth O, Noguera-Julian A, et al.; ptbnet TB Meningitis Study Group. Performance of immune-based and microbiological tests in children with tuberculosis meningitis in Europe: a multicentre Paediatric Tuberculosis Network European Trials Group (ptbnet) study. Eur Respir J. 2020;56:1902004. https:// doi.org/10.1183/13993003.02004-2019

29. Abubakar I, Pimpin L, Ariti C, Beynon R, Mangtani P, Sterne JA, et al. Systematic review and meta-analysis of the current evidence on the duration of protection by bacillus Calmette-Guérin vaccination against tuberculosis. [v-vi.]. Health Technol Assess. 2013;17:1-372, v-vi. https:/ / doi.org/ 10.3310/hta17370

30. Gafar F, Ochi T, Van't Boveneind-Vrubleuskaya N, Akkerman OW, Erkens C, van den Hof S, et al. Towards elimination of childhood and adolescent tuberculosis in the Netherlands: an epidemiological time-series analysis of national surveillance data. Eur Respir J. 2020;56:2001086. https://doi.org/10.1183/13993003.01086-2020

31. Trunz BB, Fine P, Dye C. Effect of BCG vaccination on childhood tuberculous meningitis and miliary tuberculosis worldwide: a meta-analysis and assessment of cost-effectiveness. Lancet. 2006;367:1173-80. https:/ / doi.org/10.1016/ S0140-6736(06)68507-3

32. Cernuschi T, Malvolti S, Nickels E, Friede M. Bacillus Calmette-Guérin (BCG) vaccine: a global assessment of demand and supply balance. Vaccine. 2018;36:498-506. https:// doi.org/10.1016/j.vaccine.2017.12.010

33. du Preez K, Seddon JA, Schaaf HS, Hesseling AC, Starke JR, Osman M, et al. Global shortages of BCG vaccine and tuberculous meningitis in children. Lancet Glob Health. 2019; 7:e28-9. https://doi.org/10.1016/S2214-109X(18)30474-1

34. World Health Organization. Immunization Indonesia 2021 country profile. 2021 [cited 2021 Dec 28]. https:/ / www.who. int/immunization/monitoring_surveillance/data/idn.pdf

35. Martinez L, Cords O, Horsburgh CR, Andrews JR, Acuna-Villaorduna C, Ahuja SD, et al.; Pediatric TB Contact Studies Consortium. The risk of tuberculosis in children after close exposure: a systematic review and individualparticipant meta-analysis. Lancet. 2020;395:973-84. https:/ / doi.org/10.1016/S0140-6736(20)30166-5

36. Bang ND, Caws M, Truc TT, Duong TN, Dung NH, Ha DTM, et al. Clinical presentations, diagnosis, mortality and prognostic markers of tuberculous meningitis in Vietnamese children: a prospective descriptive study. BMC Infect Dis. 2016;16:573. https:/ / doi.org/10.1186/ s12879-016-1923-2

37. Thee S, Roy RB, Blázquez-Gamero D, Falcón-Neyra L, Neth O, Noguera-Julian A, et al. Treatment and outcome in children with tuberculous meningitis - a multi-centre Paediatric Tuberculosis Network European Trials Group study. Clin Infect Dis. 2021 Nov 21 [Epub ahead of print]. https://doi.org/10.1093/cid/ciab982

38. Boyles TH, Lynen L, Seddon JA; Tuberculous Meningitis International Research Consortium. Decision-making in the diagnosis of tuberculous meningitis. Wellcome Open Res. 2020;5:11. https:/ / doi.org/10.12688/ wellcomeopenres.15611.1
39. Cresswell FV, Te Brake L, Atherton R, Ruslami R, Dooley KE, Aarnoutse R, et al. Intensified antibiotic treatment of tuberculosis meningitis. Expert Rev Clin Pharmacol. 2019; 12:267-88. https:// doi.org/10.1080/17512433.2019.1552831

40. Donald PR, Schoeman JF, Van Zyl LE, De Villiers JN, Pretorius M, Springer P. Intensive short course chemotherapy in the management of tuberculous meningitis. Int J Tuberc Lung Dis. 1998;2:704-11.

41. World Health Organization. Rapid communication on updated guidance on the management of tuberculosis in children and adolescents [cited 2021 Dec 28]. https:/ / www. who.int/publications/i/item/9789240033450

42. Ruslami R, Gafar F, Yunivita V, Parwati I, Ganiem AR, Aarnoutse RE, et al. Pharmacokinetics and safety/ tolerability of isoniazid, rifampicin and pyrazinamide in children and adolescents treated for tuberculous meningitis. Arch Dis Child. 2022;107:70-7. https:/ / doi.org/10.1136/ archdischild-2020-321426

43. Panjasawatwong N, Wattanakul T, Hoglund RM, Bang ND, Pouplin T, Nosoongnoen W, et al. Population pharmacokinetic properties of antituberculosis drugs in Vietnamese children with tuberculous meningitis. Antimicrob Agents Chemother. 2020;65:e00487-20. https:// doi.org/10.1128/AAC.00487-20

44. van Toorn R, Zaharie S-D, Seddon JA, van der Kuip M, Marceline van Furth A, Schoeman JF, et al. The use of thalidomide to treat children with tuberculosis meningitis: a review. Tuberculosis (Edinb). 2021;130:102125. https://doi.org/10.1016/j.tube.2021.102125

45. Abo YN, Curtis N, Osowicki J, Haeusler G, Purcell R, Kadambari S, et al. Infliximab for paradoxical reactions in pediatric central nervous system tuberculosis. J Pediatric Infect Dis Soc. 2021 Oct 5;piab094. https:// doi.org/10.1093/ jpids/piab094

46. Gafar F, Marais BJ, Nataprawira HM, Alffenaar JC. Optimizing antimicrobial and host-directed therapies to improve clinical outcomes of childhood tuberculous meningitis. Clin Infect Dis. 2021 Dec 15 [Epub ahead of print]. https:/ / doi.org/10.1093/cid/ciab1036

47. Schoeman JF, Van Zyl LE, Laubscher JA, Donald PR. Effect of corticosteroids on intracranial pressure, computed tomographic findings, and clinical outcome in young children with tuberculous meningitis. Pediatrics. 1997;99:226-31. https://doi.org/10.1542/peds.99.2.226

48. Rohlwink UK, Figaji A, Wilkinson KA, Horswell S, Sesay AK, Deffur A, et al. Tuberculous meningitis in children is characterized by compartmentalized immune responses and neural excitotoxicity. Nat Commun. 2019;10:3767. https://doi.org/10.1038/s41467-019-11783-9

49. Rohlwink UK, Mauff K, Wilkinson KA, Enslin N, Wegoye E, Wilkinson RJ, et al. Biomarkers of cerebral injury and inflammation in pediatric tuberculous meningitis. Clin Infect Dis. 2017;65:1298-307. https:/ / doi.org/10.1093/ cid/cix540

50. Marais BJ, Heemskerk AD, Marais SS, van Crevel R, Rohlwink U, Caws M, et al.; Tuberculous Meningitis International Research Consortium. Standardized methods for enhanced quality and comparability of tuberculous meningitis studies. Clin Infect Dis. 2017;64:501-9.

Address for correspondence: Fajri Gafar, University of Groningen, Groningen Research Institute of Pharmacy, Unit of PharmacoTherapy, Epidemiology and Economics, Antonius Deusinglaan 1 (Rm: 3214.0450), 9713 AV Groningen, The Netherlands; email: f.gafar@rug.nl, fajri.gafar@gmail.com 